\title{
MuJERES CENTROAMERICANAS QUE TRANSITAN Y LABORAN EN LA FRONTERA SUR DE MÉXICO. UNA RECONSTRUCCIÓN ANALÍTICA
}

\author{
Central American Women Who Travel and Work on the Southern Border of Mexico. An Analytic \\ Reconstruction
}

\author{
María del Carmen García-Aguilar
}

Resumen: En este artículo se analizan experiencias de mujeres centroamericanas que transitan por México y que se quedan a trabajar en la frontera sur. Se ofrece una perspectiva analítica con miras a desestructurar la parálisis en la comprensión de su problemática, y con ello propiciar alternativas de dignificación de sus condiciones de viday de trabajo a través de políticas públicas de género. Utilizando como método la fenomenología, se recupera la experiencia de vida cotidiana de estas mujeres migrantes que encaran realidades múltiples y contingentes. Se concluye con el registro de nuevas-viejas formas de representación, de proyectosy de experiencias que invocan una epistemología del "desengaño".

Palabras clave: mujeres centroamericanas migrantes, género, derechos humanos, vida cotidiana, violencia, política pública, política migratoria.

Abstract: This article analyzes the experiences of Central American women who travel through Mexico and those who stay on the southern border to work. An analytic perspective is offered not only to disentangle the current paralysis of thinking about the issues affecting these women, but to suggest ways to dignify their living and working conditions through gender-sensitive public policy changes.. From phenomenology, as a method, the article recovers the experience of everyday life of migrant women who face multiple and contingent realities. It concludes with the registration of new-old forms of representation, of projects and experiences lived and felt that invoke an epistemology of "disillusionment".

Keywords: Central American migrant women, gender, human rights, daily life, violence, public policy, migration policy.

\footnotetext{
María del Carmen García Aguilar. Doctora en Ciencias Sociales por la Universidad Autónoma Metropolitana, México. Miembro del Sistema Nacional de Investigadores nivel II. Investigadora-docente del Centro de Estudios Superiores de México y Centroamérica de la Universidad de Ciencias y Artes de Chiapas, México. Temas de investigación: relaciones de poder y cultura política. Correo electrónico: mcgarcia2005@yahoo.com.mx.
}

Enviado a dictamen: 1 de febrero de 2017. Aprobación: 26 de abril de 2017. Revisiones: 1 . 


\section{Introducción}

L a comprensión de la vida de las mujeres migrantes, atravesadas por un poder de control desde medios abiertos e inacabados, corre el riesgo de estacionarse en la repetición recurrente de un plano sintomático cuyas salidas formales se sustentan en un modelo de sociedad abierto a posibilidades dadas de humanización con principios y prácticas de igualdad y libertad. En este artículo se ofrecen los trazos de otra lectura posible, que irrumpe en este saber dado y ofrece las "líneas de fuga" de un hacer de las mujeres migrantes que entraña un desafío epistémico y político. ${ }^{1}$

El texto se organiza en tres apartados. En el primero se presenta una síntesis del conocimiento sobre el ingreso de las mujeres en la migración internacional como campo de conocimiento y como realidad vivida, con centro en las mujeres migrantes centroamericanas, que nos permite esbozar realidades y registrar ausencias analíticas y reflexivas; en el segundo se recuperan estos esbozos y ausencias para plantear la construcción de otra lectura posible, que entraña una construcción epistémica, fenomenológica y política. Se recupera el campo problemático del género, que en lenguaje político se sostiene con el reclamo de los faltantes "instituidos" y la exigencia de su "restitución". En el tercer apartado se presentan dos reflexiones finales que intentan, más allá del desideratum dominación patriarcal vs. dominación estructural, tanto un acercamiento entre pensamiento y política, como validar, con sentido imperativo, el tramado de subjetividad que, inseparable del orden de la reproducción social de las bases materiales de vida, explica lo inexplicable.

\section{Pensamiento y realidad de las mujeres migrantes del sur. Centroamericanas que transitan y trabajan en la frontera sur de México}

El documento El mapa migratorio de América Latina y el Caribe, las mujeres y el género de Martínez (2013) constituye una referencia imprescindible para conocer el campo relacional entre migración y mujeres, así como los desafíos que en materia de investigación y de política entraña el siglo XXI. ${ }^{2}$ En él se reconoce no sólo el carácter embrionario de las fuentes de la investigación y su impacto en la débil protección de los derechos de las mujeres en las fases cruciales del traslado, la inserción y el retorno, sino también la urgente necesidad de recuperar lo que pareciera irrecuperable: el conocimiento de la migración indocumentada que, en el caso de las mujeres, constata la abolición de todo límite democrático instituido tanto por la autoridad del Estado y del derecho internacional, como por las mismas sociedades de origen, tránsito y recepción.

En el recuento de lo que se sabe y cómo se sabe sobre la migración internacional femenina, nuestro autor recupera estudios que ya en los ochenta registraban la centralidad de las mujeres y la incorporación de la perspectiva de género, y en las décadas de 1990 y 2000 registraban cómo el género: “comienza a ser analizado como concepto teórico central y principio estructurador de los movimientos migratorios", producto de un "largo proceso de problematización y de formulaciones teórico-metodológicas" (Martínez, 2013). ${ }^{3}$ Sostiene, así, que la incorporación de la perspectiva de género abre un campo de realidad social que tiende a complejizar la investigación, privilegiando los estudios de caso que generalmente denotan "ambigüedad y contraposición".

Enunintentopor hacer un balance, puede decirseque los estudios sobre las mujeres migrantes internacionales han seguido dos direcciones: las investigaciones que tienden a privilegiar un enfoque normativo que articula el enfoque de género y el de los derechos humanos, y aquellas que tienden a privilegiar el enfoque procesual y a estructurarse bajo una determinada corriente teórica, situada en los debates académicos sobre las teorías y las metodologías de las migraciones del siglo XXI. Lo importante en ambas vertientes, como fundamento esencial o como eje transversal, es la recuperación del "enfoque de género", que descansa en el reconocimiento de la centralidad de las mujeres como principio estructurador de la migración mundial, contenida en la categoría "feminización migratoria" ${ }^{4} \mathrm{La}$ diferencia es que, mientras la primera tiende a enfatizar la dominación patriarcal, que define el dominio y las 
desigualdades de género, la segunda recupera también el modelo de dominación y de desigualdad estructural o sistémica. En cuanto a las realidades de las migraciones del sur, se podría plantear la recurrencia analítica de ambos modelos, aunque sin profundizar en la naturaleza de sus antagonismos - vertical y horizontal-, con tensiones entre sí, con derivados normativos, o en abierta oposición.

En conjunto, las investigaciones sobre la migración femenina mundial y regional del sur registran un campo productivo que rebasa la tradicional mirada asociacional — mujeres que acompañan o esperan-, para colocarlas como sujeto central de una actividad, la migración con fines laborales, que es un componente definitorio en la estructuración de sus vidas; con el mismo énfasis se sostiene que su incorporación a la migración, en la magnitud registrada hoy día, responde a las exigencias del mercado laboral global $y$, mayormente, a las necesidades de subsistencia de las familias pobres, hechos que son atravesados por las desigualdades de género (Mora, 2003). Incluso, también existe un consenso amplio en que, aun cuando se registren experiencias migratorias de mujeres jóvenes desligadas de la dependencia conyugal y bajo espacios laborales que flexibilizan la división sexual del trabajo, la desigualdad de género define el sentido integral de la experiencia migratoria (Martínez, 2013). Los factores y procesos contextuales que definen los rasgos más significativos de las formas de inserción de las mujeres sureñas en los circuitos migratorios y en los mercados laborales regionales, intrarregionales e internacionales, revelan también la inequidad salarial y las condiciones de precariedad laboral, generadas por el modelo económico, que se afianzan por la condición de trabajadoras "indocumentadas"

Desde el plano de la academia especializada, la investigación sobre las relaciones entre migración internacional y mujeres migrantes del sur, si bien sostiene relaciones estrechas con el campo hegemónico del género y sus vínculos con los derechos humanos y las políticas públicas, tiende a privilegiar un debate al interior de los estudiosos de la migración internacional. El impacto de la visibilidad concreta de las mujeres migrantes en un fenómeno que se pensó era exclusivo de hombres, coloca a la investigación en serios desafíos por la incorporación de la perspectiva de género y el sentido radical del pensamiento político de los feminismos. Las teorías del transnacionalismo, del capital social migratorio, de las redes sociales y de la nueva economía política se han visto fuertemente sometidas a un trabajo de reelaboración conceptual y metodológica. Se registra también un enfoque que se define por el uso de sofisticados sistemas de información y de modelos analíticos sustentados en las teorías de la rational choice, con métodos matemáticos y estadísticos que posibilitan exitosos productos académicos y que incluyen recomendaciones y proyecciones para la toma de decisiones de los países receptores, pero que dejan en la penumbra a las personas migrantes, sus proyectos y experiencias, $y$, un hecho no menor, el sentido mismo del conocimiento alcanzado.

El balance del cómo y el para qué del saber sobre este campo de realidad internacional pareciera estar formalmente establecido: el género, estructurado formalmente desde el derecho internacional de los derechos humanas, da entrada a las "políticas públicas" de los Estados nacionales y, desde este marco, se abre un campo de investigaciones con un abanico de tensiones definidas institucionalmente que serán objeto de políticas públicas bajo el estatuto de género. Conocimiento y política se articulan, y se arriba al reclamo de la "ausencia" de lo políticamente instituido. Sin embargo, la realidad social complejiza y tensa el esquema de "orden" planteado, y la investigación social, desde su diagnosis, hace visible este hecho. Veamos lo que sabemos sobre las mujeres centroamericanas que transitan y que trabajan en la frontera sur de México.

La frontera sur de México, zona de entrada de migrantes centroamericanos, de otros países del continente americano y de otros continentes, es un territorio de vida móvil, regular y de tránsito, donde se configuran relaciones de poder y de fuga, de dominio, y de resistencia o conflicto. Modula un orden social dislocado y una vida cotidiana disforme y múltiple, pero cuyo sentido está definido por la lucha por la subsistencia, y donde los poderes estatal y privado 
se han reconfigurado sobre las formas de los poderes globales, que hoy reclaman derechos a través del uso de la fuerza.

Recuperando las tesis de Mbembe (2008) sobre las dinámicas sociales y geopolíticas de las fronteras del sur global, podría afirmarse que en la frontera sur de México también se gestan dinámicas sociales definidas por los nodos de la "desposesión" y la "expulsión" deliberada de grandes contingentes de población que por ella transitan con fines de llegar a Estados Unidos. Es también una porción de territorio y lugar "vivido", con sus marcas históricas y con renovadas condiciones de pobreza y de exclusión/inclusión. En sus distintos ámbitos, la violencia y sus formas resultan, así, una consecuencia inevitable, como inevitables son las profundas dislocaciones del orden sociopolítico fronterizo, que en su extremo registra la coexistencia de una soberanía compartida, es decir, que procede de dentro y fuera del Estado nacional.

El universo de las mujeres centroamericanas en la frontera sur y en el territorio mexicano está dado, sin que se cuente con el conocimiento exacto, por miles de mujeres que intermitentemente transitan por, o trabajan en, ciudades o localidades menores de la frontera sur de México. Brevemente registraremos el mundo de vida que define sus prácticas, posiciones y despliegues de acomodo, oposición y resistencia a la expropiación del derecho a la existencia misma.

\section{Mujeres migrantes en tránsito: expulsión, infiltración o "el maldito tránsito"}

En 2013 el Gobierno mexicano detuvo a 80472 migrantes de Centroamérica. De éstos, 77216 fueron deportados (devueltos) por las autoridades migratorias, de los cuales 10494 eran mujeres (15.6\%). En 2015, el número de detenidos fue de 170 323; de esta cifra, 150 170 fueron deportados (devueltos) a su país de origen, de los que 25891 eran mujeres (21.3\%). Entre 2013 y 2015 el número de detenciones registró un incremento del $112 \%$ y el número de deportados del $95.5 \%$, de manera tal que la expulsión o repatriación de mujeres tuvo un incremento mayor, el 146.7\%. En el mismo periodo fue visible también el incremento de menores migrantes, del 252\%, que en términos absolutos pasó de 7876 a 27 707. También se registró un incremento de menores no acompañados del 158\%, al pasar de 5383 a 13914 (INM, 2013, 2014 y 2015).

Transitar por la frontera sur y el territorio mexicano hacia su frontera norte implica internarse, en cuerpo y conciencia, a un espacio y a un tiempo donde pareciera reinar el caos, donde es preciso "capturar a la presa" para expulsarla, secuestrarla, sustraerle sus escasas pertenencias, violarla o matarla. Despojada de todo poder, la persona migrante camina al filo de la navaja porque están en riesgo el proyecto anhelado que permitirá la subsistencia familiar y la vida misma (Bustamante, 2001). Las sensibilidades se alteran y la sensación de impotencia pareciera dibujar un horizonte de horror y sufrimiento inevitables. Imposible desconocer la tragedia y el sentido de desconsuelo tanto de quienes hicieron suyo el proyecto de la travesía y fueron objeto de expulsión en algún lugar del territorio de tránsito, como de las madres, esposas, padres o hermanos que claman por sus muertos y sus desaparecidos. Qué decir de quienes no padecieron la "muerte por goteo" ni el sentido abierto de la "racialización" en el lugar de residencia y de trabajo por haber muerto de inmediato en "la Bestia", o por haber sido violentada y asesinada en algún lugar del trayecto, en el que el valor de la demostración de fuerzas del crimen organizado y sus aliados es superior al valor de las personas migrantes (Sandoval, 2015).

La lista de hechos violentos y de muerte que hoy trae consigo la decisión de transitar por la frontera sur y el territorio mexicano que conduce a su frontera norte con fines de alcanzar el "sueño americano" no tiene fin. Y, más allá de la consternación, indignación o sorpresa de las autoridades y los representantes de organismos internacionales, estamos frente a hechos que han perdido el sentido de la contingencia para tornarse cotidianos y normalizados por los medios impresos, radiales y televisivos, los cuales imponen una "violencia comunicacional" que, como señala Reguillo, trunca toda comprensión y explicación que trascienda el hecho que se comunica. ${ }^{5}$ 
El drama humanitario que vive la población migrante de tránsito — que va en extremo desde la ejecución de 58 hombres y 12 mujeres transmigrantes indocumentados en San Fernando, Tamaulipas, entre el 22 y 23 de agosto de 2010, a la paliza, arrestos y robos de pertenencias, "además de la violación de dos mujeres" por parte de oficiales de la Secretaría de Marina y el Instituto Nacional de Migración en abril de 2008 en Tabasco, ${ }^{6}$ o a la muerte a manos de la Policía Federal Preventiva de dos jóvenes mujeres de Ecuador y de una persona de Guatemala, al disparar a un camión en el que viajaban 44 personas migrantes, en enero de 2009, en el municipio de San Cristóbal de Las Casas, Chiapas-va acompañado de una enorme lista de violencias y muertes que, desde las narraciones de las víctimas y familiares, hace vibrar el sentido de la impotencia y, con ella, el desconsuelo por ver devastadas la vida personal, familiar y la del entorno comunitario (García, 2011) de miles de personas. Sin embargo, la vida, esta vida de migrante irregular, continúa poblada de proyectos y decisiones desde los cuales se asume "afrontar" las condiciones de riesgo y vulnerabilidad que entraña el viaje, ocultando y suspendiendo los horrores ya sabidos, pero, como indica León:

El desconsuelo habita el interior humano, sus espacios solitarios y compartidos, cuando algo fundamental ha sido arrebatado, cuando no hay alivio alguno para lo que se experimenta. [...] Sin embargo, como cualquier criatura sentiente, no estamos hechos para el sufrimiento, aunque éste nos sea constitutivo, a pesar de que hagamos de él un mito, una salida justificatoria o un camino de entendimiento. No estamos hechos para soportar el desconsuelo, y no obstante lo habitamos [...]

El sufrimiento y el desconsuelo agudo sólo lo podemos padecer de manera intermitente o por poco tiempo, so pena de ser aniquilados. [...] tienen que atenuarse para que haya una reconciliación con el mundo y pueda ser habitable, con señalizaciones de salida, ventanas que puedan abrirse o cerrarse, y con un terreno en el que la pisada, la mente y los afectos puedan posarse sin riesgo de desbarrancarse (León, 2012: 19 y 21).
"La vida, señito" —nos dice una mujer hondureña que permanece "temporalmente" (tres años) en Chiapas, pero su "tirada" es llegar a "los Estados"-, "el sueño no va a acabar". En efecto, en palabras del director de la OIT, el fenómeno migratorio "ya es imparable" y continuará creciendo:

[...] la historia nos enseña que nada puede detener los flujos migratorios, ni las cercas ni los muros; también sabemos que no es fácil para las sociedades de destino acostumbrarse a la llegada de los trabajadores, pero tenemos que saber aprovechar las oportunidades y el potencial que representan los recursos humanos para todas nuestras sociedades (OIT, 2016).

LaOIT(2016)indicaqueenCentroamérica, particularmente en los países que conforman el Triángulo del Norte - Guatemala, El Salvador y Honduras-, se registra la incorporación creciente al fenómeno migratorio de jóvenes, niños, niñas y mujeres; y aunque el destino proyectado sigue siendo Estados Unidos, son también Costa Rica, Panamá y Belice importantes lugares de destino.

\section{Expulsión, infiltración, “acá cerquita” para estar un "poquito menos peor". Vida y trabajo en la frontera sur de México}

El universo de las trabajadoras centroamericanas en la frontera sur, mayormente de Guatemala y Honduras, si bien se significa por la diversidad de la demanda laboral, tiene como elemento común la falta de alternativas laborales y la violencia en los lugares de origen. Paradójicamente en el lugar de llegada las condiciones son similares, o quizás, como suelen decir las mujeres transfronterizas, "un poquito menos peor" que en el lugar de donde vienen. Estar en sintonía con el actual capitalismo global de "desposesión" le significa, a la economía de esta porción del sur global, sostener y renovar sus viejas prácticas de explotación laboral y de dominio.

¿Quiénes son y cuántas son? Aunque se han efectuado numerosos estudios, no existen estadísticas que nos aproximen a su cuantía real; no obstante, 
destaca una investigación con un importante soporte cualitativo, ${ }^{7}$ el documento académico Las trabajadoras migrantes en la frontera sur de México editado por El Colegio de México y ONU Mujeres (2015), que recupera los estudios pioneros de Hugo Ángeles, Martha Luz Rojas Wiesner, Manuel Ángel Castillo, Rodolfo Casillas, y del Centro de Derechos Humanos Fray Matías de Córdova, entre otros. En él se indica que, en las últimas tres décadas, dos de las transformaciones más importante de la migración internacional en la frontera sur de México son: el incremento en la cantidad de migrantes y, en ésta, la creciente incorporación de mujeres y niños, niñas y adolescentes. Estos cambios en los flujos migratorios, por su naturaleza principalmente irregular, ocasionan dificultades para su ponderación cuantitativa, de manera que una primera lectura de estos nuevos flujos deriva de la información primaria oficial, como los registros administrativos del Instituto Nacional de Migración(INM), del Censo de Población y Vivienda del Instituto Nacional de Estadística y Geografía (INEGI), y recientemente de la Encuesta sobre Migración en la Frontera Sur (Emif-Sur). No obstante, se reconoce la parcialidad de estos registros: el primero se sustenta en los ingresos documentados, sean visitantes o trabajadores/trabajadoras fronterizos; el segundo ofrece los datos de mujeres inmigrantes nacidas en los países centroamericanos, y el tercero ofrece información sobre los flujos de trabajadoras de Guatemala a México (Las trabajadoras migrantes..., 2015: 16).

En suma, el INM indica que, en los años 2010, 2011 y 2012, del total de trabajadores documentados, un aproximado de 30000 personas, el 17.4\%, 17.8\% y 16.4\% respectivamente fueron mujeres. El Censo de Población y Vivienda del INEGI, por su parte, indica que, en 2010, el número de personas radicadas en Chiapas y nacidas en el extranjero fue de 31 704, mayoritariamente de Guatemala, Honduras y El Salvador; de esta cifra, el 55\% eran mujeres. La Emif-Sur, que aporta el número de cruces migratorios laborales de guatemaltecos de 15 años y más procedentes de México-Guatemala, registró, entre los años 2014 y 2017, un promedio anual de 291000 cruces, de los que cerca de la mitad eran de trabajadores transfronterizos. En atención al sexo, la Emif-Sur destaca que las mujeres trabajadoras representaron un promedio cercano al 35\%, siendo visible que los cruces laborales de las mujeres eran principalmente hacia los centros urbanos; este sustento estadístico hace posible establecer tres tipos de flujos: el de las trabajadoras guatemaltecas documentadas, el de las trabajadoras inmigrantes y el de las trabajadoras guatemaltecas temporales y transfronterizas. ${ }^{8}$

Es posible que la misma naturaleza de la frontera, y de la movilidad laboral entre dos territorios que comparten una historia y una dinámica sociocultural similar, imposibilite un registro estadístico integral que permita ponderar la distinción genérica. No obstante, se insiste en la necesidad de efectuar esta distinción; por ahora, prima la conjunción de una investigación cualitativa que incorpora información primaria con ejercicios estadísticos particulares o de caso, lo que permite identificar, como es el caso de nuestro documento básico, el tipo de actividad que realizan las mujeres trabajadoras y sus condiciones laborales, esto es: 1) Las empleadas en la agricultura; aunque se reconoce que es el grupo más importante, con una larga presencia en el sistema de fincas y su incorporación paulatina a las actividades laborales en otros cultivos, no se conoce su magnitud global. 2) Las ocupadas en las actividades domésticas o del hogar; de este último grupo tampoco se conoce su magnitud numérica, aunque se sabe que son mayoritariamente jóvenes de los departamentos del occidente guatemalteco y que laboran en las principales ciudades de la frontera bajo condiciones que violentan toda normativa regulatoria; poco se sabe de la historicidad de este grupo de mujeres, no obstante su presencia laboral es de vieja data, lo que dota al fenómeno de un sentido normalizado, aunque no exento de tensiones por la incorporación reciente de mujeres de otros países de Centroamérica y su expansión hacia otros estados fronterizos. 3) Las trabajadoras en la industria del sexo y el entretenimiento; las estadísticas oficiales no registran su presencia, pues se invisibiliza o se encubre bajo otras actividades, no obstante, son el centro del crecimiento de bares y prostíbulos de ciudades y pueblos de la región fronteriza; provienen de países de Centroamérica, aunque se reconoce, por 
algunas encuestas, que poco más del 30\% de estas trabajadoras son mexicanas.

Tanto la estructura migratoria y de movilidad laboral, como las actividades en las que se emplean las mujeres centroamericanas, implican vida y trabajo, y también cuerpo e imaginario desde donde se diseñan, así sea con un sentido de total incertidumbre, estrategias, proyectos y experiencias de movilidad laboral en los que se registran las grandes tragedias y los pequeños triunfos y en los que se conjuga un constante "negociar". Todo ello en el escenario cotidiano de la subjetividad expropiada y negociada, oculta por las cifras y su ordenamiento analítico, que a su vez explica la existencia misma del fluir y de la regularidad de ese vivir frenético en la frontera sur de México.

Desde hace tiempo se conoce el ir y venir de las trabajadoras migrantes a la cosecha del café en las fincas de Chiapas y existen diversas percepciones sobre este movimiento. Actualmente, frente a una estructura agrícola más diversificada, a este movimiento se suman más mujeres jóvenes acompañadas de una figura familiar masculina o solas, y también, de manera creciente, de niños y niñas. Les define ese ir de finca en finca, sin morada, expuestas a atracos, humillaciones y a la codicia de los empleadores, que desdeñan el reconocimiento, como personas y colectivo, de su dignidad humana.

El trabajo de las mujeres migrantes, principalmente guatemaltecas, en las actividades del hogar, constituye un abanico de experiencias laborales en las que es posible identificar, más que diferencias, similitudes entre uno y otro lado de la frontera. Independientemente del tipo de flujo, la demanda laboral que requiere esta actividad en la frontera sur de México, pese a experiencias de "empoderamiento", se caracteriza por condiciones laborales y salariales precarias. La exigencia del salario mínimo y de prestaciones sociales por parte de las mujeres implica la negativa misma del trabajo, de ahí el reiterado "acuerdo", ajeno a la exigencia de una ley laboral salarial que no opera, ni se espera que opere, en la frontera sur.

Elllamado servicio sexual, en el que a la precariedad laboral y salarial se suman las violencias relacionales tanto de los empleadores y del abanico de "usuarios" como de la sociedad local, constituye la realidad más avasalladora y destructora de todo sentido de humanidad; las mujeres pierden la vida, pues su vida deja de ser suya desde el momento mismo en el que se establece la contratación "verbal", llena de insinuaciones prometedoras. Muerte, golpes e insultos se afianzan en la impunidad y propician la normalización del daño. No se sabe el número de mujeres que realizan este tipo de trabajo, tampoco sus destinos, aquí y ahora, iquién sabe en qué lugar mañana! Lo visible, que es el espectáculo de "chicas felices" por lo que hacen, arroja en la oscuridad el dolor y las infamias de una articulación entre el dominio patriarcal y el sistémico que hace posible una diversidad de daños innombrables.

Las mujeres que cruzan la frontera con permisos de veinticuatro o más horas son la argamasa de la vida social fronteriza. Forjan un vivir fronterizo, con todas las pasiones encontradas, para encarar su "disolución" por poderes que están más allá de su voluntad, y desarrollan, como indica Goldberg (2012), una capacidad negociadora en un cotidiano vivir crítico. El latido de la frontera es, así, la recurrencia de un ir y venir trayendo consigo la mercadería que las define como "vendedoras ambulantes"; lo es también el reiterado empeño de la palabra para trabajar en una diversidad de actividades, que se materializan en múltiples formas de dominio, explotación y estrategias de negociación para que ello sea posible, negociación que no necesariamente implica la superación radical de las afectaciones sufridas ni la afectación de las instituciones y sus leyes. Sin embargo, ese actuar dual que hace posible la vida de miles de mujeres centroamericanas no se explica si no asumimos el carácter dislocado de la frontera, donde la ley y las normas, stricto sensu, son lo anómalo.

La frontera sur de México se despliega como lugar y territorio. ${ }^{9}$ Formalmente convoca a tres países México, Guatemala y Belice-, bajo una semántica estatal que conjuga soberanía, autodeterminación, poder legítimo y un "nosotros" frente a los "otros", vectores que activan los valores del nacionalismo que definen los imaginarios del territorio "propio" e inviolable, y legitiman los términos de la separación y el contacto. No obstante, la frontera concreta, representada, vivida 
y subjetivada, registra un fondo histórico, lingüístico y cultural de continuidad que es hoy amenazado y minado por decisiones de geopolítica que afianzan el interés de "fronteras cerradas", cuyas consecuencias están alterando el conjunto de las dinámicas sociopolíticas del territorio y las sociabilidades e instituciones que las hacen posibles.

Las formas de articulación de ambos lados de la frontera sur son producto de haber compartido una historia y una vida casi común. En ambos lados la percepción de la gente es la de un "allá más de lo mismo", o, tal vez, de un "allá [lado mexicano] un tantito mejor" y de un "aquí [lado guatemalteco], un poco peor". La percepción tradicional de una frontera abierta, sin línea divisora concreta en tanto continuidad social, está cambiando ante el crecimiento de la violencia atribuida al narcotráfico y a la migración de tránsito y de destino. ${ }^{10}$ Lo común en cuanto a paisaje, naturaleza, cultura e historia es violentado por la globalización y sus nuevos actores.

Hoy la frontera sur de México está estructuralmente marcada por su inserción en el mundo global, cuyas representaciones sobre la modernidad, con sus utopías de desarrollo o progreso, recurrentemente se disuelven para, ante el recrudecimiento de los vectores opuestos - pobreza, exclusión, violencia—, dar vida a proyectos y experiencias de movilidad, desplazamientos y migraciones que, en su mayoría, derivan de un aprendizaje de lo incierto y contingente. No es un hecho menor sostener que las mujeres migrantes en esta parte de la frontera sur, que han modulado la desarticulación del orden pasado, hoy construyen escenarios sociales que arrebatan a los poderes globales porciones de un atraco mayor orientado a la disolución y fragmentación de colectivos mayoritarios.

\section{Otra lectura posible: vida “ordinaria" y política}

Los destellos de realidad que definen la vida de las mujeres migrantes, pero ausentes de lógica analítica, son razón para sostener la necesidad de una construcción investigativa que ponga en suspenso los vectores clásicos con los que comprendemos y explicamos el acontecer de lo social de las migrantes. Como sugiere Goldberg con la noción de "gente de polvo", entendiendo el polvo como "una condición socio-natural de la vida y sus limitaciones" (2012: 15), el punto de partida es formular una interrogante: si la vulnerabilidad y el riesgo acompañan la decisión de emigrar, y si las condiciones de precariedad extrema son la constante del diario vivir, ¿qué factores explican el creciente peso que vienen ejerciendo las mujeres migrantes del sur en la migración internacional?

La búsqueda de respuesta a esta pregunta abreva del conocimiento del "ser" y "hacer ordinario" de las mujeres migrantes, en espacios vividos desde donde activan sus precarios capitales, y se reestructuran y estructuran formas societarias e identidades restringidas, recurrentemente provisionales y múltiples (De Certeau, 2000). Se trata, como acto cognitivo y evaluativo, de un campo de subjetivación y sensibilidad" cuyos elementos se encuentran en permanente desequilibrio, y des-configuran y reconfiguran las formas de categorizar a los demás y a uno mismo (Dubar, 2002). Entraña "ser" y "hacer ordinario", un ámbito de producción de "subjetivación" y de "sustracción" que posibilita enfrentar condiciones adversas que, como la precariedad extrema y la violencia normalizada, implican la tarea imparable de "negociar" el derecho de vida; en sus intersticios entraña también la construcción de una "biopolítica menor" o de esa "comunidad que viene"12 (Agamben, 2006; Goldberg, 2012; Deleuze y Guattari, 2010; León, 2012).

El breve registro del ser y hacer de las mujeres migrantes revela que estamos frente a nuevas condiciones de aprehensión y representación; que los proyectos y las experiencias vividas y sentidas como personas y colectivo inauguran una "nueva" epistemología que Goldberg (2012) define como “epistemología del desengaño" y "autodesengaño". El vivir de cada una de ellas, como personas y colectivo, no abraza el mito del desarrollo, pero han aprendido a negociar con el poder político institucionalizado, y sus engaños y simulaciones - Estado de bienestar democrático-, cuando se trata de mejorar condiciones laborales y calidad de vida decorosa. 
Para las mujeres en tránsito y para las que trabajan en la frontera sur, las transformaciones de las últimas tres décadas han implicado cambios drásticos en el universo de significados que alteran su comprensión del mundo y de sí mismas. Interiorizar, desafiar y dislocar las fuerzas que las oprimen y violentan constituye un campo de producción social aún inexplorado en las ciencias sociales, anclado a un pensar que no logra acomodo en el presente. La diada sociedad/Estado, hoy sociedad/economía, como ordenadoras de las ciencias sociales, y asumidas como entidades autónomas y distintas que definen, bajo mecanismos consensuales, el campo de las disputas por el poder y la lucha por las hegemonías, pierde su frontera formal y analítica tornándose, en lo local, incapaz de explicar, siguiendo el argumento de Abrams, el "enorme poderío político" del agente migratorio $\mathrm{X}$, para retener y expulsar, aludiendo, sin más, al interés exclusivo del Estado en cuestión (Abrams, Gupta y Mitchell, 2015: 26).

Se arriba así a marcos de relaciones recuperados desde los espacios cotidiano u ordinario, donde se despliegan discursos y prácticas que permiten entender la naturaleza del dominio estatal, fincado en procesos de sujeción política bajo el imperativo de la "legitimación de lo ilegítimo", cuyo despliegue en el mundo de lo social sólo es posible desde la "dislocación" de las instituciones convertidas en "agencias de Estado" (Abrams, Gupta y Mitchell, 2015: 53). En síntesis, se asume que las instituciones operan, pero lo hacen "dislocándose", y ello es posible no sólo por la visibilidad de sus aporías, sino por los intercambios, permutas y negociaciones permanentes entre los portadores del poder instituido y la sociedad local, y en ella, las mujeres. En los intersticios de esa conjugación entre "deber ser" y "ser" se produce un campo de prácticas y subjetividades que se activa por la fuerza de lo contingente y lo inminente, que hace posible ese mundo social. ${ }^{13}$

Ese afán por impulsar una investigación "situada" y "desde abajo", por recuperar la historicidad de las formas del desengaño para inquirir en el tiempo presente en "su hacer en y a través de sus falsificaciones", se torna en una exigencia, pues:
El neo-con-liberalismo - la hiperextenuación del neoliberalismo, que he llamado neo-neoliberalismoen su corazón (si tiene uno) reescribe el guion histórico como simulación, como falsedad. La "simulación" sirve tanto como compulsión, como coacción, como imposición forzada sin importar las consecuencias, que como una cubierta cosmética de las deformidades y mundos-polvo que se producen (Goldberg, 2012: 22).

Esta tesis decanta en la propuesta de una epistemología que clausura las promesas del progreso y hace del desengaño y del autodesengaño "un conocer en, y a través de negaciones, de engaños y amenazas [...]". Lo propio del neo-neoliberalismo, en términos de Goldberg, es la condición generalizada de la "precariedad extrema" no como algo temporal, sino como vivencia ordinaria cuyo despliegue práctico es la multiplicación de las condiciones de posibilidad precaria que apuntan a otras formas de vida y a otras elaboraciones simbólicas de orden, rehusándose a la disolución que como destino instituyen los poderes globales. En tanto nuevas condiciones de aprehensión y representación, se puede afirmar que estamos frente a "una precariedad tanto epistemológica, como ontológica" (Chávez, 2012: 8; Goldberg, 2012: 21):

Aquí, la "lectura sintomática" es sólo un primer paso, dejando la puerta abierta a estas co-habitaciones, un pasar a través de (el espejo de) las partículas de polvo para confrontar esta contra-sociabilidad más o menos directa en las condiciones de sus posibilidades y en el ser de sus expresiones habitadas, en todo arremolinamiento de polvo y no sólo sintomáticamente. Como también debe serlo la contra-condición, que metafóricamente llamaré (a falta de un mejor nombre) una vida "verde" (Goldberg, 2012: 21-22).

Pero el desafió, además de epistemológico y fenomenológico, es político. Pensar desde el sur implica cuestionar de manera crítica la producción conceptual 
y el universo de sentido que se nos imponen como sociedad en particular. Destaquemos el discurso que, desde la ONU y los Estados socios, vindica la garantía del respeto a los derechos de la igualdad de género. A este respecto, Martínez (2013), recupera la definición de la categoría de género del documento Compilación seleccionada del marco jurídico nacional e internacional de la mujer (2004) ${ }_{1}^{14}$ y registra no sólo la inexistencia de un debate sobre género, sino la "ubicación de ésta en el enclave de uno de sus usos y finalidades prácticos, es decir, como definición consensuada". Se refiere, en el plano normativo, al consenso que sostiene que: "el problema de la inequidad y la violencia contra las mujeres" se debe encarar racionalmente, con sentido de "suficiencia", por medios "legales y políticas públicas" (Martínez, 2013: 31).

En esta perspectiva, el género como enfoque se construye "desde la finalidad de buscar un cierto grado cero en las instancias de los acuerdos en torno al género [...]", reducido a la función de "consensuar las diferencias de interés y opinión de los expertos y de los posibles usuarios de las reglamentaciones internacionales" (Martínez, 2013: 27 y 28). La deconstrucción crítica que la autora realiza de la definición de género en el documento citado le lleva a sostener que el "consenso" es un instrumento que niega la pluralidad; que el género es un "proceso", no un producto, y que la reinscripción de la violencia en el plano social, opuesto al plano político, lleva a legitimar las acciones centralizadas del gobierno, expropiando lo colectivo y sus derechos "de toma de decisiones antes de que puedan llevarse a efecto". Un último registro hace referencia al tratamiento de la violencia de género que "la quiere erradicada de la vida colectiva", como si ésta fuera "natural" y "exterior" al escenario político (Martínez, 2013: 29).

Esta lectura crítica de los sustentos jurídiconormativos de la igualdad de género, que exige el cumplimiento de mandatos jurídicos y la instrumentación de políticas públicas sin alterar las tensiones de naturaleza estructural, como las propias del modelo patriarcal o de género, abre posibilidades para construir un pensamiento sobre las mujeres que recupere el sentido vertical de sus tensiones y permita recuperar, con sentido propositivo, los contenidos contestatario y radical de los feminismos. ${ }^{15}$

\section{Reflexiones para un pensamiento políticamente posible}

El desiderátum en que nos deja el discurso oficial, dominación patriarcal vs dominación estructural, tiene consecuencias en la definición de prácticas y estrategias, pues éstas conllevan el "poder" para producir efectos políticos. Por ello, es crucial su distinción analítica y política. Indiquemos que el concepto núcleo de la primera, la dominación patriarcal, es el de "género", que se entiende como la diferencia socialmente construida entre lo masculino y lo femenino, construcción que, si bien apela al sentido temporal "civilizatorio", también apela a una cultura "situada" (Sau, 2000). Desde esta perspectiva, la interrogante gira en torno a si la perspectiva de género y el feminismo institucional irrumpen y trastocan dimensiones sistémicas o son construcciones de un pensamiento global-neoliberal resuelto a administrar, en sus propios términos, los conflictos, las luchas por la subsistencia y el mismo derecho de vida, tensando la frontera entre ambos modelos de dominación que son, para el caso de las mujeres migrantes del sur, "dominaciones inseparables" y al margen de todo privilegio de "primero lo uno y luego lo otro" (Varela, 2008: 9).

La deconstrucción de la perspectiva de género y el feminismo institucional, como pensamiento y acción política, que no es otra cosa que la desnaturalización de su ropaje neoliberal, deriva en un desnudo que hace referencia a la recuperación de una sensibilidad que es necesario descifrar desde el "ser" y "hacer" de la mujer como persona y como colectivo y, desde estos puntos, tejer las mediaciones que hagan posible la operación de los contenidos del discurso teórico-político del feminismo, ${ }^{16}$ interiorizados en interrogantes válidas para las realidades de las mujeres del sur, entre éstas: ¿por qué están excluidas las mujeres?, ¿por qué los derechos sólo corresponden a la mitad del mundo?, ¿dónde está el origen de esta discriminación?, ¿qué podemos hacer para combatirla? (Varela, 2008: 10). 
Las respuestas "situadas" a estas interrogantes devienen en posibilidades analíticas para considerar tanto las diferencias entre las mujeres del mundo desarrollado de Occidente y las mujeres del sur, como el acercamiento de ambas bajo la idea de la "precarización" como la "regla del tiempo global neoliberal" y como "forma de regular del poder" (Lorey, 2016); también la posibilidad de dirigir la naturaleza del tratamiento analítico y político a un problema de realidad, bajo el paraguas de la "perspectiva de género" y del "feminismo institucional". No se trata sólo de reconocer que estas últimas son narrativas conceptuales y políticas que intentan compensar los déficits de legitimidad de una gobernabilidad, otrora "gobernanza internacional" dotada de sentido de universalidad, y desde esa intencionalidad definir el umbral de sus prácticas que evitan trastocar el orden instituido, sino fundamentalmente de encarar la construcción de un pensamiento de género y de un "feminismo institucional" desde la problematización de su despliegue concreto, esto es, en su centro y en su periferia, pero también en el centro y en la periferia, como dimensiones socio-espaciales históricamente situadas.

En esta perspectiva, Butler es conclusiva al sostener que el feminismo -o los feminismos- pasa por la interrogante acerca de lo humano para estar en condiciones de resignificar los conceptos de la vida sexual y de género, y de alertar de los riesgos de un feminismo que quede "inequívocamente con la imposición de valores en contextos culturales deliberadamente ignorados" (Butler, 2009). Plantea, así, los desafíos que implica una renovada politización teórico-práctica, esto es: "lograr que el feminismo se deshaga de sus presupuestos de Primer Mundo y usar los recursos de la teoría y activismo feminista para volver a pensar el significado del lazo, el vínculo, la alianza, la relación, tal como son imaginados y vividos en el horizonte de un contraimperialismo igualitario" (Butler, 2009: 69).

Una última reflexión, así sea un breve esbozo, hace referencia a nuestro presente como "tiempo de subjetividad" (Cruz, 1996: 13), subjetividad que hizo posible la explicación y comprensión de una práctica, la de emigrar, que de antemano se sabe incierta, riesgosa, precaria y sujeta a las prácticas más violentas de los "otros" por estar en tierra que no es la propia. Quien emigra hoy de forma "irregular" pareciera hacerlo negando realidades, aferrándose quizás a "Dios" que, como figura totalizante de sentido, hace posible que la persona se aventure a lo desconocido bajo la idea de someterse a sus designios que, en tanto le son positivos, le ayudan a sostener la fuerza interior para enfrentar los desafíos.

En el tiempo global, esa identidad, como realidad fundante del sujeto configurada por ese hacer "para sí y frente a los otros" (Cruz, 1996: 13), se construye en los migrantes con materiales de "polvo" que hacen de la cultura una dimensión simbólica e imaginaria forjada desde la contingencia y lo inminente, desde la pérdida de los vectores que definen el lugar y lo propio, y desde los referentes relacionales con los "otros". Sin embargo, por su fragilidad, ante la pérdida de una precaria seguridad ontológica, la persona migrante conjura y reafirma su identidad, sabiéndola precaria, pero sin renunciar a su derecho de ser y de vida, aunque ello signifique una identidad en vilo y oscilante.

Para el caso que nos ocupa, el desafío analítico consiste en dejar en suspenso esa subjetividad que, desde el amplio espectro de la cultura, dota de identidades relativamente sólidas al sujeto, y en recuperar desde el fluir de la vida cotidiana, local y ordinaria, lo propio de la globalización y de sus materiales disolventes y fragmentarios, esto es, las subjetividades identitarias a las que a su naturaleza ambigua, por su particularismo oculto, se suman otras formas de significar el mundo y su orden (Balibar, 2005). Así, la subjetividad de los actores del concierto de la migración internacional no sólo es un construir identitario en permanente desequilibrio en su hacer para sí, y para o frente a los otros, sino es también un construir discursivo diferencial, mutable y en flujo continuo, esto es, ajeno a lo planificado, unilineal e irreversible (González, 1996: 33).

En suma, es la categoría de "subjetividad", junto alade "sujeto", la que posibilita entender un comportamiento que pareciera ser, o es, el arrojo a un juego entre la vida y la muerte, un juego que define la realidad migrante 
del mundo global como un "acontecimiento", esto es, una acción de ruptura, de invención o de creación imposible e indecible, de desborde, que adviene en un lugar concreto y se piensa como estratos de una realidad práctica situada y espacializada que "hace posible el levantamiento del inexistente" (Badiou, 2012: 77).

Es cierto que entre sus características prima la precariedad extrema y la violencia normalizada, y, en torno suyo, un hacer en el que pesa la fuerza de lo inmediato, de lo inminente y de lo que Cruz define como el "adelgazamiento del terreno de la experiencia compartida y el sentido de desbordamiento" (Cruz, 1996). Es cierto, también, que detrás de las experiencias migratorias de hoy se revelan horrores que impiden recuperar cualquier sentido de normalidad. No obstante, lo que hace de la migración internacional, mayormente irregular, un acontecimiento es la producción, por parte de sus actores, de una subjetividad que, como emplazamiento en el mundo social, encara la amenaza de la "disolución" de la persona sin mediación de ningún derecho humano y de ninguna política pública, lo que crea nuevas condiciones de aprehensión y representación que contraamenazan el orden instituido. La migración recupera ese "otro social" que está conformado por muchos otros, construidos desde la precariedad extrema material, como condición ordinaria, lo que implica reconocer la precariedad epistemológica y ontológica que hoy define la investigación social y nos desafía a pensar y hacer investigación desde esa pequeñez de lo social que devela la banalidad de la democracia liberal como soporte de algo que es falso de origen, al igual que su mito: el capitalismo de rostro humano.

\section{Notas}

${ }^{1}$ Este trabajo es parte de una investigación sobre violencia y globalización en el Sur, que inicié en mi año sabático (2016) en el Instituto de Ciencias Sociales y Humanas "Alfonso Vélez Pliego" de la Benemérita Universidad Autónoma de Puebla.

2 De un total de 45 millones de migrantes en Estados Unidos, más de 21 millones son de América Latina. En atención a once corredores, la feminización de la migración laboral se significa: las mujeres son más del $50 \%$, en su mayoría en situación irregular, lo que decanta en la economía informal, con nulo o bajo acceso de protección social y precariedad en las condiciones de empleo, además de que sufren abuso, explotación y discriminación" (OIT, 2016).

3 Destacan, entre otros, los estudios de Jiménez (1998); Lim y Oishi (1996); Lim (1998); Sutcliffe (1998); Ariza (2000); Oishi (2002); Mora (2003); Villa y Martínez (2002); Staab (2003); Boyd y Grieco (2003); y Chant (ver: Martínez, 2003).

${ }^{4}$ Esta categoría hace referencia al incremento constante de la migración femenina mundial y regional que iguala o supera a la de los hombres, a la búsqueda de independencia laboral, y a la emergencia de nuevos patrones migratorios como las cadenas globales de cuidado y familias distantes (Araiza, 2000; Bastia, 2008; OIT, 2010 y 2015).

${ }^{5}$ En ésta, "[...] el lenguaje naufraga, se agota en el acto mismo de tratar de producir una explicación, una razón; las violencias hacen colapsar nuestros sistemas interpretativos, pero al mismo tiempo, estos cuerpos rotos, vulnerados, violentados, destrozados con saña, se convierten en un mensaje claro: acallar, someter. Silencio control que, desde la violencia total amenaza en el territorio mexicano sin contención alguna" (Velasco, 2016).

${ }^{6}$ Cuarto Poder, 14 de abril de 2008.

${ }^{7}$ La mayor parte de los estudios y diagnósticos sobre las mujeres centroamericanas trabajadoras en la frontera sur de México son relativamente recientes. Destacan trabajos de cientistas sociales de ECOSUR, CIESAS y el CESMECA-UNICACH, y de organizaciones no gubernamentales como IMUMI, INCIDE y otras. Un lugar especial ocupa ONU-Mujeres, que en estrecha colaboración con investigadores de El Colegio de México impulsa la investigación sobre la realidad de las mujeres migrantes en la frontera sur de México (ver: Las trabajadoras migrantes..., 2015; Díaz et al., 2015).

${ }^{8} \mathrm{Al}$ respecto, ver: Castillo y Nájera (2016) y Anguiano y Cruz (2016).

9 "[...] un lugar es el orden de acuerdo con el cual los elementos se distribuyen en relaciones de coexistencia. Un lugar, tal y como señala Michel de Certeau, es 
una configuración instantánea de posiciones. Implica estabilidad. En cuanto al territorio, es fundamentalmente una intersección de cuerpos en movimientos. Se define en esencia por el conjunto de movimientos que tiene lugar dentro de él [...] constituye un conjunto de posibilidades a las que se resisten o que realizan una y otra vez actores históricamente situados" (Mbembe, 2008: 169).

${ }^{10}$ Según un informe divulgado por la OIM en Ciudad de Guatemala, tan sólo en 2015 México deportó a 36568 mujeres procedentes del Triángulo Norte de Centroamérica, mientras que en 2012 el total de deportaciones de mujeres centroamericanas fue de 7081. En el caso de Estados Unidos, la cifra de mujeres migrantes deportadas pasó de 6749 en 2012, a 9858 en 2016 (La Prensa Gráfica, 2017).

11 "[...] el ámbito de lo sensible no supone meras reacciones fisiológicas al entorno o, en otras palabras, el cuerpo no reacciona ciegamente al ambiente, siempre existe una carga de sentido: sentir es desde ya darle significado al mundo" (Sabido, 2009: 39).

12 "Biopolítica menor," lo opuesto a la biopolítica sistémica; abre un espacio de vida comunitaria que hace uso de lo existente - el derecho- sin reivindicarlo. Lo inventa el cual sea, "expropiado de toda identidad para apropiarse de la pertenencia misma”, enfrentando el poder donde se ejerce. En suma, la "comunidad que viene es la reunión, frágil como el chispazo de un rayo, de esos cualquiera que ninguna legitimidad podría mantener sometidos" (Agamben, 2006:16)

13 "La condición de dis-locación [...] es la fuente y expresión de su ilegibilidad engendrando, tal vez, una crisis de representación social y de control. Las condiciones de la vida cotidiana [...], ya no pueden ser dadas por sentadas, ni puede asumirse que entreguen, aseguren o garanticen - como lo hizo alguna vez el Estadolas bases de las condiciones diarias de existencia, más allá de la simple supervivencia o de mantener a raya al desnudo" (Goldberg, 2012: 21).

${ }^{14}$ El enfoque de género "[...] hace referencia a los roles, responsabilidades y oportunidades asignados al hecho de ser hombre y ser mujer y a las relaciones socioculturales entre mujeres, hombres y niñas y niños. Estos atributos, oportunidades y relaciones están socialmente construidos y se aprenden a través del proceso de socialización. Son específicos de cada cultura y cambian a lo largo del tiempo, entre otras razones, como resultado de la acción política" (Compilación seleccionada..., 2004: 28).

${ }^{15}$ Sustentados en las filosofías feminista de la "igualdad" (Nancy Fraser, Celia Amorós, Iris Young), la "diferencia” (Carla Lonzi, Milagros Rivera, Hélene Cixous, Rosi Braidotti) y el feminismo postestructuralista (Julia Kristeva, Biddy Martin) que impulsó la construcción de la subjetividad generizada (Zambrini, 2010).

${ }^{16}$ Entre los que destacan: su abierta oposición al orden establecido; ser una teoría y una práctica articulada por mujeres en lucha por la justicia; ser una filosofía política y un movimiento social "no dirigido y escasamente, por no decir, nada, jerarquizado; y una ética y una forma de estar en el mundo" (Varela, 2008: 9).

\section{Referencias bibliográficas}

Abrams, Philip, Akhil Gupta y Timothy Mitchell (2015). Antropología del Estado. México: FCE.

Abrams, Philip (2015). "Notas sobre la dificultad de estudiar el Estado". En Philip Abrams, Akhil Gupta y Timothy Mitchell, Antropología del Estado. México: FCE, pp. 17-70.

Agamben, Giorgio (2006). La comunidad queviene. Valencia: Pre-Textos.

Araiza, M. (2000). Ya no soy la que dejé atrás... Mujeres migrantes en República Dominicana. México: ISS, Plaza y Valdez.

Anguiano Téllez, María Eugenia y Rodolfo Cruz Piñeiro (2016). "Flujos migratorios en tránsito por México desde el Triángulo norte de Centroamérica". En Anguiano Téllez María Eugenia y Daniel Villafuerte Solís (coords.), Migrantes en tránsito a Estados Unidos. Vulnerabilidades, riesgos y resiliencia. México: COLEF, UNICACH, pp. 45-69.

Bastia, Tanja (2008). "La feminización de la migración trasnacional y su potencial emancipatorio". En Papeles, 104, septiembre: 67-77.

Badiou, Alain (2012). El despertar de la historia. España: Clave Intelectual. 
Balibar, Étienne (2005). Violencia, identidades y civilidad. Para una cultura política global. Barcelona: Gedisa.

Bustamante, Jorge (2001). "Un marco conceptual de referencia acerca de la vulnerabilidad de losmigrantes como sujetos de los derechos humanos". En Teresa Fernández de Juan (coord.), Los rostros de la violencia. México: El Colegio de la Frontera Norte, pp. 19-53.

Butler, Judith (2009). Vida precaria. El poder del duelo y la violencia. Argentina: Paidós.

Castillo, Manuel Ángel y Jéssica Nájera A. (2016). "Centroamericanos en movimiento: medios, riesgos, protección y asistencia”. En Anguiano Téllez María Eugenia y Daniel Villafuerte Solís (coords.). Migrantes en tránsito a Estados Unidos. Vulnerabilidades, riesgos y resiliencia. México: COLEF, UNICACH, pp. 71-98.

Chávez Mac Gregor, Helena (2012). "Aproximaciones para una crítica de la violencia”. En Elena Chávez Mac Gregor (ed.), Estética y violencia: necropolítica, militarización y vidas lloradas. México: MUAC, UNAM, pp. 6-11.

Compilación seleccionada del marco jurídico nacional e internacional de las mujeres (2004). México: Secretaría de Relaciones Exteriores, UNIFEM, PNUD.

Cruz, Manuel (1996). "Introducción. Ese extraño problema que nos constituye". En Manuel Cruz (comp.), Tiempos de subjetividad. Barcelona: Paidós, pp. 9-16.

De Certeau, Michel (2000). La invención de lo cotidiano I. Artes de hacer. México: Universidad Iberoamericana.

Deleuze, Gilles y Félix Guattari (2010). Mil mesetas. Capitalismo y esquizofrenia. Valencia: Pre-Texto.

Díaz Prieto, Gabriela et al. (2015). Las trabajadoras migrantes centroamericanas en Chiapas. Recomendaciones de políticas públicas para garantizar el ejercicio de sus derechos. México: IMUMI, ONU MUJERES.

Dubar, Claude (2002). La crisis de las identidades. La interpretación de una mutación. Barcelona: Bellaterra.

García Aguilar, María del Carmen (2011). "Violencia y ética. A propósito de la migración irregular y los derechos humanos". En VillafuerteSolís, Daniel y María del Carmen García Aguilar (coords.), Migración, seguridad, violencia y derechos humanos. Lecturas desde el Sur. México: UNICACH, PROMEP, Miguel Ángel Porrúa, pp. 79-126.
Goldberg, David Theo (2012). "Epistemología del desengaño. Tipologías de lo extra-ordinario”. En Helena Chávez Mac Gregor (ed.), Estética y violencia: necropolítica, militarización y vidas lloradas, México: MUAC, UNAM, pp. 15-30.

González, José María (1996). "El individuo y la sociedad". En Manuel Cruz (comp.). Tiempos de subjetividad. Barcelona: Paidós, pp. 9-38.

INM (Instituto Nacional de Migración) (2013). 2013 Boletín estadístico mensual. México: INM. Disponible en: http://www.politicamigratoria.gob.mx/es_mx/ SEGOB/Boletin_Estadistico_2013.

INM (Instituto Nacional de Migración) (2014). 2014 Boletín estadístico mensual. México: INM. Disponible en: http://www.politicamigratoria.gob.mx/es_mx/ SEGOB/Boletin_Estadistico_2014.

INM (Instituto Nacional de Migración) (2015). 2015 Boletín estadístico mensual. México: INM. Disponible en: http://www.politicamigratoria.gob.mx/es_mx/ SEGOB/Boletin_Estadistico_2015.

Las trabajadoras migrantes en la frontera sur de México. Hacia una agenda de Investigación (2015). México: El Colegio de México, ONU Mujeres.

León, Émma (2012). "La templanza y el silencio discriminante". En Emma León (coord.), Virtudes y sentimientos sociales para enfrentar el desconsuelo. Madrid: CRIM-UNAM, SEQUITUR, pp. 17-43.

Lorey, Isabell (2016). Estado de inseguridad. Gobernar la precariedad. Madrid: Tradiciones de Sueños.

Martínez Pizarro, Jorge (2003). El mapa migratorio de América Latina y el Caribe, las mujeres y el género. Chile: ONU, CEPAL.

Martínez de la Escalera, Ana María (2013). “Crítica de una categoría: género (contribución al debate)”. En Ana María Martínez de la Escalera y Erika Lindig Cisneros (coords.), Alteridades y exclusiones. Vocabulario para el debate social y político. México: Facultad de Filosofía y Letras-UNAM, Juan Pablos Editor, pp. 27-39.

Mbembe, Achille (2008). "Al borde del mundo: fronteras, territorialidad y soberanía en África”. En Sandro Mezzadra (comp.), Estudios postcoloniales. Ensayos fundamentales. Madrid: Traficantes de Sueños, pp. 167-236. 
Mora, Luis (2003). Las fronteras de la vulnerabilidad: género, migración y derechos sexuales y reproductivos. S.l. Fondo de Población de Naciones Unidas. Disponible en: http:// www.cepal.org/celade/noticias/paginas/2/11302/ lmora.pdf.

OIT (2010). Informe sobre las migraciones en el mundo 2010. El futuro de la migración: creación de capacidades para el cambio. Francia: Courand et Associés.

OIT (2015). Informe sobre las migraciones en el mundo 2015. Los migrantes y las ciudades: nuevas colaboraciones para gestionar la movilidad. Francia: OIT

OIT (2016). "OIT alerta sobre necesidad de mejorar la gobernanza de la migración laboral en América Latina y el Caribe". México: OIT, 30 de agosto 2016. Disponible en: http://www.ilo.org/americas/sala-deprensa/WCMS_516597/lang--es/index.htm.

Sabido, Olga (2009). "El extraño”. En Emma León Emma (ed.), Los rostros del otro. Reconocimiento, invención y borramiento de la alteridad. México: Anthropos, CRIMUNAM, pp. 25-57

Sandoval García, Carlos (2015). No más muros. Exclusión y migración forzada en Centroamérica. Costa Rica: Instituto de Investigaciones Sociales-Universidad de Costa Rica.

Sau, Victoria (2000). "“De la facultad de ver al derecho de mirar". En Marta Segarra y Ángel Carabi (eds,), Nuevas masculinidades. España: Caria, pp. 29-40.

Varela, Nuria (2008). Feminismo para principiantes. España: Ediciones B.S.A.

Velasco Villanueva, Deico (2016). "La epistemología del desencanto ante las violencias comunicacionales". En Aureavisura, 4(20), octubre-diciembre. Disponible en: http://aureavisurarevista.fad.unam.mx/?p=2639.

Zambrini, Laura (2010)."Modos de vestir e identidades de género. Reflexiones sobre las marcas culturales en el cuerpo". En Nomadías, 11:130-149. 